\title{
Effects of Aerobic and Anaerobic Fatigue Exercises on Postural Control and Recovery Time in Female Soccer Players
}

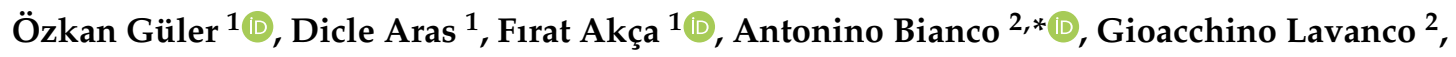 \\ Antonio Paoli ${ }^{3}$ (D) and Fatma Neşe Şahin ${ }^{1}$ \\ 1 Faculty of Sports Sciences, Ankara University, Gölbaşı, Ankara 06830, Turkey; oguler@ankara.edu.tr (Ö.G.); \\ daras@ankara.edu.tr (D.A.); fakca@ankara.edu.tr (F.A.); nesesahin@ankara.edu.tr (F.N.Ş.) \\ 2 Department of Psychological, Pedagogical, Educational Science and Human Movement, University of \\ Palermo, 90144 Palermo, Italy; gioacchino.lavanco@unipa.it \\ 3 Department of Biomedical Science, University of Padova, 35122 Padova, Italy; antonio.paoli@unipd.it \\ * Correspondence: antonino.bianco@unipa.it; Tel.: +39-091-23896910
}

Received: 4 August 2020; Accepted: 24 August 2020; Published: 28 August 2020

\begin{abstract}
Sixteen female soccer players (age $=20.19 \pm 1.52$ years; body mass $=56.52 \pm 4.95 \mathrm{~kg}$; body height $=164.81 \pm 4.21 \mathrm{~cm}$ ) with no history of lower extremity injury participated in the study. The Biodex SD Balance system was used to determine the non-dominant single-leg stability. In anaerobic exercise, each subject performed four maximal cycling efforts against a resistance equivalent to $0.075 \mathrm{~kg} / \mathrm{body}$ mass for $30 \mathrm{~s}$ with three-minute rest intervals. In aerobic exercise, subjects performed the Bruce protocol on a motorized treadmill. After each exercise, subjects subsequently performed a single-leg stability test and then repeated the same test for four times with five-minute passive rest periods. In accordance with the results, it was found that the impairment observed right after the aerobic loading was higher $(p<0.001)$ compared to the anaerobic one. However, the time-related deterioration in both aerobic and anaerobic loadings was similar. The B-pre value was lower than $\mathrm{B}_{\text {post }}$ and $\mathrm{B}_{5}(p<0.01)$ and $\mathrm{B}_{10}(p<0.05)$ in both conditions. Subjects could reach the initial balance level at $B_{15}$ after aerobic and anaerobic loadings. The lactate level did not reach resting value even after $20 \mathrm{~min}$ of both fatigue protocols. Although the fatigue after aerobic and aerobic exercise negatively affects a single-leg dynamic balance level, single leg balance ability returns to the baseline status after $10 \mathrm{~min}$ of passive recovery duration.
\end{abstract}

Keywords: balance; fatigue; female; support leg; recovery

\section{Introduction}

The popularity of soccer among females is increasing each passing day. It is estimated that around 30 million females are actively playing licensed soccer in more than 100 countries around the world. Studies indicate that as the participation of females in soccer increases, the incidence of injury increases at a high rate [1-3]. In a soccer match, soccer players engage in many moves such as high-intensity acceleration, deceleration, sudden change of direction, bounce, and other soccer-oriented movements. Along with these moves, soccer players often experience various injuries when using one leg for stopping and cutting during pressure, while using the other leg to tackle the ball [4]. In addition to these, injuries in soccer are caused by sudden acceleration and deceleration without impact, rapid disorientation, and exposure to high loads while maintaining the stability of the knee joint in unpredictable movements [5-8]. When the injuries experienced in soccer were evaluated according to sex differences, It was reported that female athletes had a higher incidence of anterior cruciate 
ligament (ACL) experience in lower extremity injuries due to biomechanical and neuromuscular differences [5,6] than males [9].

Furthermore, previous studies indicate that female soccer player has the risk of ACL injury nine times greater than males [10]. Several risk factors cause these injuries in female soccer players. These risk factors in female soccer players include a previous history of injury [11], as well as a decline in hip strength [12] due to accumulated fatigue [11] and deterioration of lower extremity dynamic balance [13]. Epidemiological studies have pointed out that $50 \%$ of the injuries occur at the end of competitions or sports activities, and $58 \%$ of these injuries are due to non-impact conditions. That fatigue is an essential element of sensory-motor changes associated with injury [14,15]. Ekstrand et al. [9] report in their study that traumatic injuries occur more often in the last minutes of both halves of a soccer match [9]. In addition to these, it was reported in another study that lower extremity injuries were commonly seen at the last minutes of competition in sports such as soccer, which includes high-intensity moves and multi-directional sprints $[9,16]$. Therefore, it can be stated that non-contact injuries caused by fatigue occurred in the last fifteen minutes of play in both the first and second half of games. In non-contact injuries, neuromuscular fatigue is seen as a risk factor [17-20]. Neuromuscular fatigue is divided into two, according to the intensity and duration of exercise, like peripheral and central nervous system fatigue. Long-term activities affect the central nervous system, while short-term high-intensity activities cause peripheral fatigue [21,22]. Peripheral fatigue arises when there is not adequate energy provided to the muscles, despite the increasing energy need [22].

Moreover, it has been reported that muscle fatigue affects both peripheral and central proprioceptive processes [23-25]. Balance is defined as being able to hold the body center of gravity within the center of support [26]. In order to maintain balance visual, vestibular, and proprioceptive systems play a crucial role, and these systems are affected by many factors [27-32]. The proprioceptive system consists of the Golgi tendon organ, the muscle spindle, the Pacini corpuscle, free nerve endings, and the receptors in the joint capsules and skin [32-34]. It ensures maintenance of the balance with the information collected from these structures [32,34]. The proprioceptive system is affected by fatigue, aging, sarcopenia, neurological disease fibromyalgia, cancer, and rheumatological diseases and may result in impaired balance [35-38]. Many researchers have shown that fatigue negatively affects dynamic postural control [39-42]. Fatigue is an essential factor that acutely affects balance ability. In a study in which the center of pressure (COP) was measured before, in halftime and immediately after a soccer match, it was determined that the balance skill of the support leg was impaired in the post-match measurement [41]. The return of balance ability to average values after fatigue depends on many factors. The return of post-fatigue balance ability to initial level depends on the duration, intensity, and type of intensity of the fatigue protocol performed [43]. Deficits in dynamic postural control is a risk factor in experiencing falls and lower extremity injuries [13,42,44-47]. The deterioration of dynamic balance is associated with reactive and compensating movements, and it is stated that this impairment has been linked to falling risk and lower extremity injuries $[18,48,49]$. Since fatigue increases the rate of injury in athletes $[9,16]$, and the lack of postural control is a lower extremity injury risk factor $[13,50,51]$, it can be expected that the rate of injury as a result of fatigue-induced postural control (fatigue-induced balance deficits) may increase.

Soccer is classified as both an aerobic and an anaerobic sport. In the game, players may experience fatigue from time to time as a result of aerobic and anaerobic activities. There are studies in the literatüre on the effects of anaerobic fatigue on balance performance in soccer players. However, up to date, no previous studies have examined the effects of both types of fatigue in soccer players. Besides, many activities such as passing, kicking, and jumping in soccer are carried out on the support leg. This research will be the first to examine the effects of fatigue on support leg balance performance. Therefore, this study aims to determine the effects of different fatigue protocols on balance performance of the support-leg in female soccer players and to understand the time required for the balance to recover after loading. 


\section{Materials and Methods}

Sixteen sub-elite female soccer players (with mean age of $20.19 \pm 1.52$ years, body mass $56.52 \pm 4.95 \mathrm{~kg}$, body height $164.81 \pm 4.21 \mathrm{~cm}$, percent body fat $22.63 \pm 2.42 \%$, and $\mathrm{maxVO}_{2}$ $52.33 \pm 5.74 \mathrm{~mL} . \mathrm{kg} .{ }^{-1} \mathrm{~min}^{-1}$ ) participated in the study voluntarily. Players who suffered lower extremity injuries for the last six months were not included in the study. Participants were instructed not to perform exercises that may cause exhaustion $48 \mathrm{~h}$ before the tests and not to use stimulants such as alcohol, caffeine, or drugs in the last $24 \mathrm{~h}$ before the study. The study was conducted according to the Declaration of Helsinki and was approved by the Ethics Committee of Ankara University, Approval code 21-1300-17, released in December 2017.

\subsection{Balance Test}

The participants were invited to participate in the Biodex SD Balance System (Biodex, Shirley, NY, USA) athletic single-leg testing protocol [52]. As noted, the Biodex Balance System (BBS) uses a circular platform that is free to move in the anterior-posterior and medial-lateral axes simultaneously. The BBS measures, in degrees, the tilt about each axis during dynamic conditions and calculates an overall stability index (OSI). A high score in the OSI indicates poor balance. The platform stability ranges from 1-12, with 1 representing the most significant instability.

The familiarization protocol was implemented before the experiments. All participants were instructed to perform the balance test on five different days of the targeted week.

The athletic single leg test protocol consisted of 3 trials of $20 \mathrm{~s}$ of upright stance on support-leg with $10 \mathrm{~s}$ of rest intervals between trials. Participants were asked to place their feet with the malleolar axis aligned with the midpoint of the platform over the center dot of the platform in a comfortable position. An athletic single-leg test was conducted on BBS with the platform set at level 4 . Balance tests were carried out on the non-dominant leg. The same test protocol was performed before $\left(\mathrm{B}_{\text {pre }}\right)$ and right after $\left(B_{\text {post }}\right)$ both aerobic and anaerobic fatigue protocols, and repeated at the 5 th $\left(B_{5}\right)$, 10th $\left(B_{10}\right)$, 15th $\left(\mathrm{B}_{15}\right)$, and 20th $\left(\mathrm{B}_{20}\right)$ minutes. The participants were allowed to rest passively during the 5 min of recovery periods. There was a 2-day period between aerobic and anaerobic fatigue protocols (Figure 1).

\subsection{Aerobic Fatigue Protocol}

The Bruce protocol was performed on a motorized treadmill (Cosmed, Rome, Italy) in order to create aerobic fatigue in soccer players [53]. The participants continued the test until they were exhausted. At the end of the test, the $\max \mathrm{VO}_{2}$ consumption values of the participants were calculated and recorded. Rating of perceived exertion (RPE) was obtained using the 6-12 point Borg scale at the end of every load [54]. $\mathrm{MaxVO}_{2}$ was defined as the highest $30 \mathrm{~s}$ average in oxygen uptake and maximal heart rate (HRmax) as the highest every $10 \mathrm{~s}$ average during the Bruce protocol. A test was considered maximal when four of the following criteria were completed: VO2 plateau at peak exercise, respiratory exchange ratio $\geq 1.10$ greater age-predicted maximal heart rate (220-age), and an indication of 18-20 rating on the Borg RPE scale [55].

\subsection{Anaerobic Loading Protocol}

Anaerobic fatigue protocol was performed using a bicycle ergometer (Monark Erogomedic 894 E Peak Bike Vansbro Sweden). The Wingate test protocol was used for anaerobic fatigue. In the Wingate protocol, participants were asked to pedal at maximal speed for $30 \mathrm{~s}$. As the intensity of the training, a weight equivalent to $7.5 \%$ of the participants' body mass was placed on the load scale. Once the participants started pedaling, the scale dropped when the bike's wheel revolution went up to $150 \mathrm{rpm}$ and the maximal pedaling for $30 \mathrm{~s}$. Soccer players were verbally motivated during training. Participants repeated the Wingate test protocol a total of 6 times with intervals of $4 \mathrm{~min}$. 


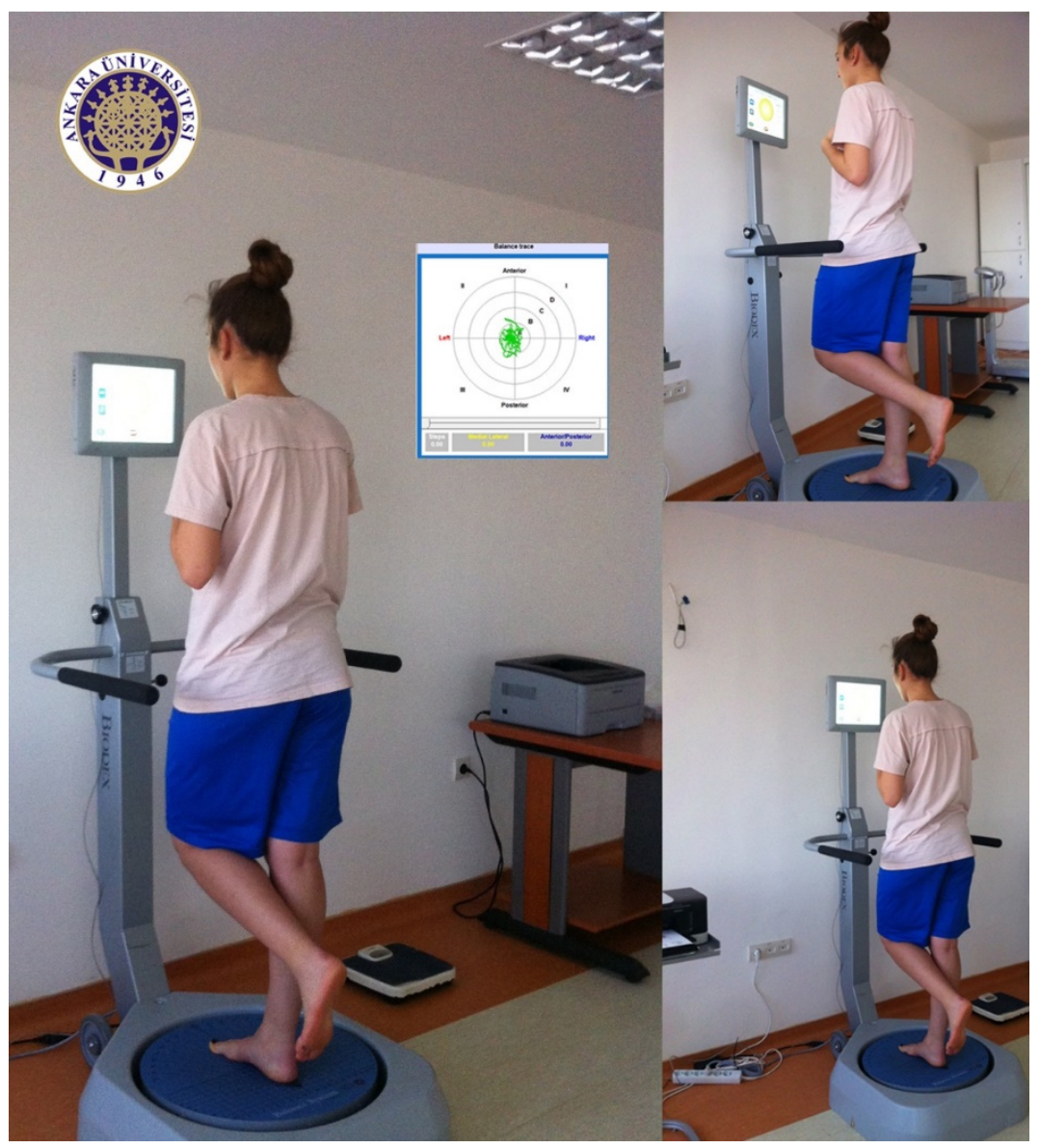

Figure 1. One subject during the data collection phase. Female soccer player.

\subsection{Lactate Testing}

Participants' blood lactate values were determined immediately after the fatigue protocol and during the recovery period $\left(\mathrm{L}_{\text {pre }}\right)$ just before the balance tests at 0 th $\left(\mathrm{L}_{\text {post }}\right), 5$ th $\left(\mathrm{L}_{5}\right), 10$ th $\left(\mathrm{L}_{10}\right), 15$ th $\left(\mathrm{L}_{15}\right)$, and 20th $\left(\mathrm{L}_{20}\right)$ minutes. During the lactate test, participants' fingertips were wiped with alcohol-based tissue paper, and their capillary blood samples were taken with a lancet pen. Blood lactate levels of the participants were determined by an Accutrend Plus lactate device (Roche Diagnostics, Basel, Switzerland).

\subsection{Statistical Analysis}

In all statistical analyses, SPSS version 20 was used (SPSS Inc., Chicago, IL, USA). First, because the number of participants was below 50, the normality of the data was analyzed with the Shapiro-Wilk test. Depending on the distribution, lactate and balance values obtained at different times following aerobic and anaerobic fatigue protocols were compared by the Paired Sample t-Test or Wilcoxon Test. For the intergroup analyzes, either the Repeated Measurements Analysis of Variance (Aerobic Lpre, L5, L10, L15, L20; Bpre, B5, B15, B20; Anaerobic Lpost, L5, L10, L15, L20; Bpre, B5, B15, B20) or the Friedman test (Aerobic Lpost, Bpost, B10; Anaerobic Lpre, Bpost, B10) was used again depending on the distribution. In the case of the dataset exhibited both non-normally distributed and norma distributed data, we proceeded with the non-parametric analysis. In all statistical analyses, the alpha value was considered to be 0.05 . 


\section{Results}

The following variables were shown to be not normally distributed (Aerobic Lpost, Bpost, B10; Anaerobic Lpre, Bpost, B10).

The lactate values obtained from the participants before, during, and after aerobic and anaerobic fatigue protocols are shown in Table 1.

Table 1. Mean comparisons of participants with lactate and balance, which vary depending on aerobic and anaerobic loading. In horizontal, the repeated measures $p$ values, in vertical the $p$ values for aerobic vs. anaerobic comparisons.

\begin{tabular}{|c|c|c|c|c|c|c|c|}
\hline $\begin{array}{l}\text { Fatigue } \\
\text { Protocol }\end{array}$ & $\mathbf{L}_{\text {pre }}$ & $\mathrm{L}_{\text {post }}$ & $\mathbf{L}_{5}$ & $\mathrm{~L}_{10}$ & $\mathrm{~L}_{15}$ & $\mathrm{~L}_{20}$ & $p_{-}$ \\
\hline Aerobic & $1.20 \pm 0.36$ & $11.70 \pm 2.53$ & $11.81 \pm 2.51$ & $9.86 \pm 2.58$ & $7.84 \pm 2.15$ & $6.93 \pm 1.87$ & $0.000 * *$ \\
\hline Anaerobic & $1.18 \pm 0.33$ & $15.43 \pm 2.40$ & $15.09 \pm 2.27$ & $13.76 \pm 2.50$ & $11.25 \pm 2.14$ & $9.49 \pm 2.51$ & $0.000^{* *}$ \\
\hline$p_{-}$ & 0.823 & 0.001 ** & $0.000^{* *}$ & $0.000 * *$ & 0.000 ** & $0.001 * *$ & - \\
\hline $\begin{array}{l}\text { Fatigue } \\
\text { Protocol }\end{array}$ & $B_{\text {pre }}$ & B $_{\text {post }}$ & $\mathbf{B}_{5}$ & $\mathbf{B}_{10}$ & $\mathbf{B}_{15}$ & $\mathbf{B}_{20}$ & $p_{-}$ \\
\hline Aerobic & $0.89 \pm 1.39$ & $2.29 \pm 1.04$ & $1.35 \pm 0.29$ & $1.08 \pm 0.35$ & $1.01 \pm 0.24$ & $1.04 \pm 0.26$ & $0.000^{* *}$ \\
\hline Anaerobic & $0.90 \pm 1.40$ & $1.58 \pm 0.57$ & $1.16 \pm 0.21$ & $1.02 \pm 0.28$ & $0.95 \pm 0.15$ & $0.98 \pm 0.18$ & $0.000^{* *}$ \\
\hline$p_{-}$ & 0.745 & 0.001 ** & 0.014 * & 0.308 & 0.410 & 0.509 & - \\
\hline
\end{tabular}

According to the results, there was no significant difference between participants' resting lactate concentration values obtained before aerobic and anaerobic loading $(p>0.05)$. However, the lactate values obtained immediately after, 5 th, 10 th, 15 th, and 20th min were statistically significant $(p<0.01)$ according to the fatigue conditions. After anaerobic loading, lactate values were found to be higher. Besides, it was understood that 20 min was not sufficient for the recovery, regardless of the type of loading.

Lactate values obtained at six different phases of the aerobic fatigue protocol were significantly different $(p<0.01)$. The resting lactate value was determined to be lower than all others reached after loading. Also, a significant difference was found between $\mathrm{L}_{\text {post }}$ and $\mathrm{L}_{10}, \mathrm{~L}_{15}$ and $\mathrm{L}_{20} ; \mathrm{L}_{5}$ and $\mathrm{L}_{10}, \mathrm{~L}_{\text {post }}$ $\mathrm{L}_{15}$, and $\mathrm{L}_{20} ; \mathrm{L}_{10}$ and $\mathrm{L}_{15}$ and $\mathrm{L}_{20}(p<0.01)$; and with $\mathrm{L}_{5}$ and $\mathrm{L}_{20}(p<0.05)$.

In lactate values measured after anaerobic loading, the resting value was determined to be significantly lower than in all other measurements. The difference between $\mathrm{L}_{\text {post }}$ and $\mathrm{L}_{5}$ was not significant, similar to the aerobic one. However, a significant difference at the level of $p<0.01$ was found between $\mathrm{L}_{\text {post }}$ and $\mathrm{L}_{10}, \mathrm{~L}_{15}$, and $\mathrm{L}_{20}$, between $\mathrm{L}_{5}$ and $\mathrm{L}_{10}, \mathrm{~L}_{15}$, and $\mathrm{L}_{20}$ and between $\mathrm{L}_{15}$ and $\mathrm{L}_{20}$.

When the results related to the balance were examined, a significant difference was found at the level of $p<0.01$ between the balance values obtained immediately after aerobic and anaerobic loading and at the 5th minute. It was understood that there is more deterioration in the balance after aerobic loading. No significant difference was observed in the values obtained after 10th, 15th, and 20th min, depending on the type of loading (Figure 2).

When the values obtained due to aerobic loading are taken into account, it was understood that the differences between $\mathrm{B}_{\text {pre }}$ and $\mathrm{B}_{\text {post }}, \mathrm{B}_{5}(p<0.01)$, and between $\mathrm{B}_{\text {pre }}$ and $\mathrm{B}_{10}$ were $(p<0.05)$ statistically significant. However, there was no significant difference with the values reached between $B_{15}, B_{20}$, and $\mathrm{B}_{\text {pre. }}$. Accordingly, it can be stated that recovery takes place after aerobic load in the state of balance between 10th and 15th minutes. In the other results, on the other hand, a significant difference was found between $B_{\text {post }}$ and $B_{5}, B_{10}, B_{15}$, and $B_{20}(p<0.01)$. The measurement of $B_{5}$ was found to be significantly higher than the measurements of $\mathrm{B}_{10}, \mathrm{~B}_{15}$ and $\mathrm{B}_{20}(p<0.01)$. 


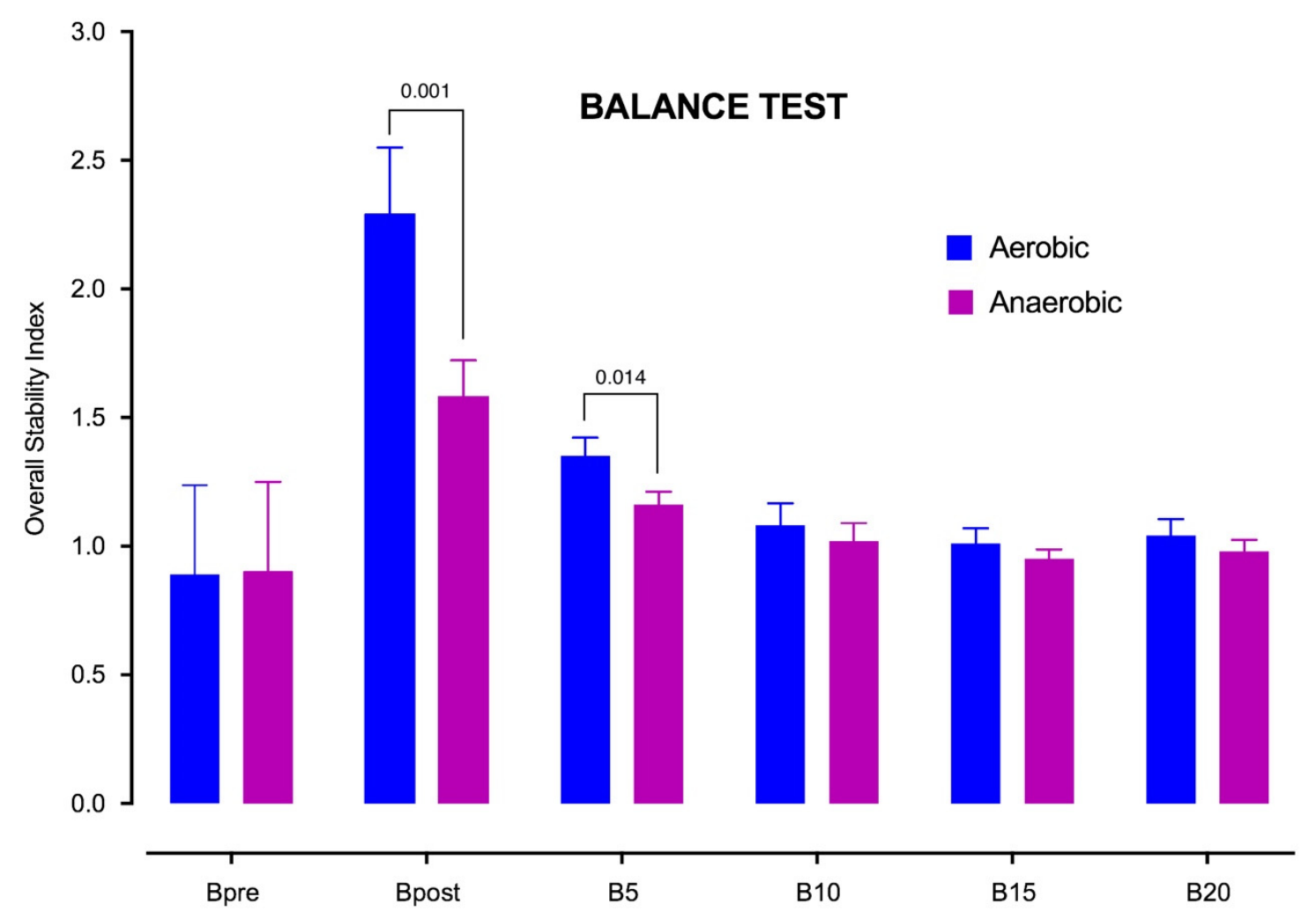

Figure 2. Overall stability index across the experimentation. Aerobic condition vs. anaerobic condition.

\section{Discussion}

This study aimed to investigate the acute effects of aerobic and anaerobic exercises on dynamic balance skill and recovery time in female soccer players. In order to control the fatigue level, lactate concentrations of the subjects were also collected. According to the lactate test results, both fatigue protocols were found to be successful in creating fatigue. Although it was higher after the anaerobic exercise, the lactate level did not return to the initial level within $20 \mathrm{~min}$ after both fatigue conditions. Besides, as a result of strenuous aerobic or anaerobic exercise, female soccer players' ability to balance the support leg was affected negatively. After both aerobic and anaerobic loading, the recovery time of balance skill lasted about $10 \mathrm{~min}$. The deterioration in the athletic single-leg stability test was observed to be higher after the aerobic fatigue protocols in all of the measurements. Furthermore, the difference was statically significant in $\mathrm{B}_{\text {post }}(p<0.01)$ and $\mathrm{B}_{5}(p<0.05)$ values. In the literature, many studies suggest that aerobic and anaerobic fatigue negatively affect balance ability [41-43,56-61]. There are similar studies on this subject in the literature. In a study in which both aerobic and anaerobic fatigue protocol was implemented, and the balance level was determined with the Balance Error Scoring System (BESS), no difference was found between the balance performance and its time of recovery after both fatigue protocols. However, athletes returned to their initial balance performance values within 8-13 min after both fatigue protocols [58]. Steinberg et al. investigated the balance level after a Yo-Yo test with the Interactive Balance System (Tetrax) device and reported that balance skill returned to the initial level within $10 \mathrm{~min}$ after fatigue [62]. In the current study, balance skills returned to the initial level after approximately $10-15 \mathrm{~min}$ after both aerobic and anaerobic fatigue. Moreover, the present study found no difference between balance levels during the recovery time after aerobic or anaerobic fatigue. In a study conducted on a bicycle ergometer, participants performed two maximal Wingate tests lasting $30 \mathrm{~s}$ with a rest interval of $2 \mathrm{~min}$. At the end of high-intensity activation, it was determined that balance skill was affected negatively and returned to the baseline level within $10 \mathrm{~min}$ [63]. Ishizuka et al. applied the functional fatigue protocol to 14 male and 9 female college-level soccer players and determined the balance with the Biodex Limit of Stability 
Test. As a result, the subjects were found to have returned their initial level within 10 min after the fatigue [59]. In a study by Matsuda et al., a functional fatigue protocol was applied to 100 recreationally active college students. After the functional fatigue protocol, it was reported in the measurements made with the balance error score system that the balance performance returned to its initial level within approximately $20 \mathrm{~min}$ [64]. Although a similar fatigue protocol was implemented, different balance performance recovery times were observed between the study mentioned above and our study. This difference is thought to be since soccer players have a better balance skill than other athletes and sedentary people. Contrary to the result of the current study, it is reported in some studies that the recovery time of balance ability lasts longer than $10 \mathrm{~min}$, while in some studies, it is reported that balance ability is not affected after fatigue. In a study where the fatigue protocol involving sports activities was applied, it was reported that the participants' balance values returned to their initial values after $20 \mathrm{~min}$ as a result of the balance test conducted with the balance error score system [56]. In another study, in which balance measurements were made after a 25-min treadmill run, it took approximately $15 \mathrm{~min}$ for the athletes participating in the study to return their balance performance to its initial level [65]. In another study, where balance measurement was performed with the biodex balance system before and during a soccer match, it was determined that the dominant leg balance performance of the players was impaired while no change was observed in the support leg balance performance [66]. In contrast to this, soccer players' support leg balance skills were found to be negatively affected following the fatigue protocol in the present study. The reason for the difference is thought to be due to the degree of difficulty differences between the protocols of balance tests. In the literature, some studies did not observe any changes experienced in balance performance after fatigue. After soccer-specific fatigue [67] and after soccer training [68], balance measurements made with the Biodex Balance System have reported that the balance performance of soccer players is not affected by fatigue. Paillard reported that the return of post-fatigue balance ability to initial values depends on the duration, density, and intensity of the fatigue protocol performed [43]. In these studies, it is thought that the reason why there is no difference after fatigue is due to insufficient density and intensity of the fatigue protocol for impaired balance ability. In addition, longer times to return to initial values of balance performance were reported in these studies compared to the current study. The reason for these varied results may have been the difference between the branches of the athletes participating in the studies or the difference in balance measurement methods.

\section{Conclusions}

As a result of this study, it was clearly observed that balance performance is impaired in soccer players after both aerobic and anaerobic fatigue. The impairment of fatigue and balance performance are seen as significant risk factors. Although there is not enough data on the effects of fatigue on balance ability in soccer players, it is stated in several studies that fatigue increases the incidence of injury experienced [69] and that deterioration in balance performance may increase ankle injuries [70]. Many researchers also suggest that balance training should be performed to prevent injuries $[1,71,72]$. Therefore, trainers should give importance to balance training in order to prevent non-contact injuries caused by loss of balance. In future studies, it is suggested to investigate the effects of fatigue on the balance ability in athletes performing balance training.

The study was performed exclusively on healthy young adult female soccer players (who suffer from a higher prevalence of non-contact ACL injuries). A limitation of the study could be seen as a lack of control of the menstrual cycle. In addition, in this study, anaerobic fatigue protocol was performed with a bicycle ergometer and aerobic fatigue with a treadmill. The measurement of balance performance after a real soccer match is thought to provide a clearer picture of the effects of soccer-specific fatigue mechanisms on balance performance.

Author Contributions: Conceptualization, Ö.G.; Data curation, D.A. and F.A.; Formal analysis, Ö.G. and F.N.Ş.; Funding acquisition, G.L.; Investigation, D.A.; Methodology, Ö.G., F.A., and F.N.Ş.; Project administration, A.B. and F.N.Ş.; Supervision, G.L. and A.P.; Visualization, A.P.; Writing-original draft, D.A., F.A., and F.N.Ş.; 
Writing—review \& editing, A.B. and A.P. All authors have read and agreed to the published version of the manuscript.

Funding: This research received no external funding.

Conflicts of Interest: The authors declare no conflict of interest.

\section{References}

1. Emery, C.; Meeuwisse, W.H.; Hartmann, S.E. Evaluation of risk factors for injury in adolescent soccer: Implementation and validation of an injury surveillance system. Am. J. Sports Med. 2005, 33, 1882-1891. [CrossRef] [PubMed]

2. Faude, O.; Junge, A.; Kindermann, W.; Dvorak, J. Injuries in female soccer players: A prospective study in the German national league. Am. J. Sports Med. 2005, 33, 1694-1700. [CrossRef] [PubMed]

3. Mtshali, P.; Mbambo-Kekana, N.; Stewart, A.; Musenge, E. Common lower extremity injuries in female high school soccer players in Johannesburg east district. S. Afr. J. Sports Med. 2009, 21, 163-166. [CrossRef]

4. Waldén, M.; Krosshaug, T.; Bjørneboe, J.; Andersen, T.E.; Faul, O.; Hägglund, M. Three distinct mechanisms predominate in non-contact anterior cruciate ligament injuries in male professional football players: A systematic video analysis of 39 cases. Br. J. Sports Med. 2015, 49, 1452-1460. [CrossRef]

5. Hewett, T.E.; Myer, G.D.; Ford, K.R.; Heidt, R.S.; Colosimo, A.J.; McLean, S.G.; Bogert, A.V.D.; Paterno, M.V.; Succop, P. Biomechanical measures of neuromuscular control and valgus loading of the knee predict anterior cruciate ligament injury risk in female athletes: A prospective study. Am. J. Sports Med. 2005, 33, 492-501. [CrossRef]

6. McLean, S.G.; Samorezov, J.E. Fatigue-induced ACL injury risk stems from a degradation in central control. Med. Sci. Sports Exerc. 2009, 41, 1662-1673. [CrossRef]

7. Smith, H.C.; Vacek, P.; Johnson, R.J.; Slauterbeck, J.R.; Hashemi, J.; Shultz, S.; Beynnon, B.D. Risk factors for anterior cruciate ligament injury: A review of the literature-Part 1: Neuromuscular and anatomic risk. Sports Health 2012, 4, 69-78. [CrossRef]

8. Olchowik, G.; Czwalik, A. Effects of soccer training on body balance in young female athletes assessed using computerized dynamic posturography. Appl. Sci. 2020, 10, 1003. [CrossRef]

9. Ekstrand, J.; Hägglund, M.; Walden, M. Epidemiology of muscle injuries in professional football (soccer). Am. J. Sports Med. 2011, 39, 1226-1232. [CrossRef]

10. Gwinn, D.E.; Wilckens, J.H.; McDevitt, E.R.; Ross, G.; Kao, T.C. The relative incidence of anterior cruciate ligament injury in men and women at the united states naval academy. Am. J. Sports Med. 2000, 28, 98-102. [CrossRef]

11. Dvorák, J.; Junge, A.; Chomiak, J.; Graf-Baumann, T.; Peterson, L.; Rösch, D.; Hodgson, R. Risk factor analysis for injuries in football players. Am. J. Sports Med. 2000, 28, 69-74. [CrossRef] [PubMed]

12. Khayambashi, K.; Ghoddosi, N.; Straub, R.K.; Powers, C.M. Hip muscle strength predicts non-contact anterior cruciate ligament injury in male and female athletes: A prospective study. Am. J. Sports Med. 2016, 44, 355-361. [CrossRef] [PubMed]

13. Plisky, P.J.; Rauh, M.J.; Kaminski, T.W.; Underwood, F.B. Star excursion balance test as a predictor of lower extremity injury in high school basketball players. J. Orthop. Sports Phys. Ther. 2006, 36, 911-919. [CrossRef]

14. Hawkins, R.D.; Hulse, M.A.; Wilkinson, C.; Hodson, A.; Gibson, M. The association football medical research programme: An audit of injuries in professional football. Br. J. Sports Med. 2001, 35, 43-47. [CrossRef] [PubMed]

15. Woods, C.; Hawkins, R.; Hulse, M.; Hodson, A. The Football Association Medical Research Programme: An audit of injuries in professional football: An analysis of ankle sprains. Br. J. Sports Med. 2003, 37, 233-238. [CrossRef] [PubMed]

16. Lundblad, M.; Walden, M.; Magnusson, H.; Karlsson, J.; Ekstrand, J. The UEFA injury study: 11-year data concerning 346 MCL injuries and time to return to play. Br. J. Sports Med. 2013, 47, 759-762. [CrossRef]

17. Yu, B.; Kirkendall, D.; Taft, T.; Garrett, W., Jr. Lower extremity motor control-related and other risk factors for non-contact anterior cruciate ligament injuries. Instr. Course Lect. 2002, 51, 315.

18. Alentorn-Geli, E.; Myer, G.D.; Silvers, H.J.; Samitier, G.; Romero, D.; Lázaro-Haro, C.; Cugat, R. Prevention of non-contact anterior cruciate ligament injuries in soccer players. Part 1: Mechanisms of injury and underlying risk factors. Knee Surg. Sports Traumatol. Arthrosc. 2009, 17, 705-729. [CrossRef] 
19. Verschueren, J.; Tassignon, B.; De Pauw, K.; Proost, M.; Teugels, A.; Van Cutsem, J.; Roelands, B.; Verhagen, E.; Meeusen, R. Does acute fatigue negatively affect intrinsic risk factors of the lower extremity injury risk profile? A systematic and critical review. Sports Med. 2019, 50, 767-784. [CrossRef]

20. Han, J.; Anson, J.; Waddington, G.S.; Adams, R.; Liu, Y. The role of ankle proprioception for balance control in relation to sports performance and injury. BioMed Res. Int. 2015, 2015, 1-8. [CrossRef]

21. Millet, G.Y.; Lepers, R. Alterations of neuromuscular function after prolonged running, cycling and skiing exercises. Sports Med. 2004, 34, 105-116. [CrossRef] [PubMed]

22. Glaister, M. Multiple sprint work. Sports Med. 2005, 35, 757-777. [CrossRef] [PubMed]

23. Forestier, N.; Teasdale, N.; Nougier, V. Alteration of the position sense at the ankle induced by muscular fatigue in humans. Med. Sci. Sports Exerc. 2002, 34, 117-122. [CrossRef]

24. Vromans, M.; Faghri, P.D. Electrical stimulation frequency and skeletal muscle characteristics: Effects on force and fatigue. Eur. J. Transl. Myol. 2017, 27, 239-245. [CrossRef] [PubMed]

25. Gentil, P.; Campos, M.H.; Soares, S.; Costa, G.D.C.T.; Paoli, A.; Bianco, A.; Bottaro, M. Comparison of elbow flexor isokinetic peak torque and fatigue index between men and women of different training level. Eur. J. Transl. Myol. 2017, 27, 246-250. [CrossRef]

26. Yaggie, J.A.; Campbell, B.M. Effects of balance training on selected skills. J. Strength Cond. Res. 2006, 20, 422-428.

27. Patti, A.; Bianco, A.; Şahin, N.; Sekulic, D.; Paoli, A.; Iovane, A.; Messina, G.; Gagey, P.M.; Palma, A. Postural control and balance in a cohort of healthy people living in Europe. Medicine 2018, 97, e13835. [CrossRef]

28. Hrysomallis, C. Balance ability and athletic performance. Sports Med. 2011, 41, 221-232. [CrossRef]

29. Eisen, T.C.; Danoff, J.V.; Leone, J.E.; Miller, T.A. The effects of multiaxial and uniaxial unstable surface balance training in college athletes. J. Strength Cond. Res. 2010, 24, 1740-1745. [CrossRef]

30. Coscia, F.; Gigliotti, P.V.; Piratinskij, A.; Pietrangelo, T.; Verratti, V.; Foued, S.; Diemberger, I.; Illic, G.F. Effects of a vibrational proprioceptive stimulation on recovery phase after maximal incremental cycle test. Eur. J. Transl. Myol. 2019, 29, 8373. [CrossRef]

31. Lin, S.; Sun, Q.; Wang, H.; Xie, G. Influence of transcutaneous electrical nerve stimulation on spasticity, balance, and walking speed in stroke patients: A systematic review and meta-analysis. J. Rehabilit. Med. 2018, 50, 3-7. [CrossRef]

32. Proske, U. Exercise, fatigue and proprioception: A retrospective. Exp. Brain Res. 2019, 237, $2447-2459$. [CrossRef] [PubMed]

33. Puh, U.; Dečman, M.; Palma, P. Vsebina in učinki programov proprioceptivne vadbe za spodnje ude-pregled literature. Fizioterapija 2016, 24, 50-58.

34. Proske, U.; Allen, T. The neural basis of the senses of effort, force and heaviness. Exp. Brain Res. 2019, 237, 589-599. [CrossRef]

35. Vantieghem, S.; Bautmans, I.; Tresignie, J.; Provyn, S. Self-perceived fatigue in adolescents in relation to body composition and physical outcomes. Pediatr. Res. 2017, 83, 420-424. [CrossRef] [PubMed]

36. Larsson, L.; Degens, H.; Li, M.; Salviati, L.; Lee, Y.I.; Thompson, W.; Kirkland, J.L.; Sandri, M. Sarcopenia: Aging-related loss of muscle mass and function. Physiol. Rev. 2019, 99, 427-511. [CrossRef] [PubMed]

37. Coletti, D. Chemotherapy-induced muscle wasting: An update. Eur. J. Transl. Myol. 2018, 28, $153-157$. [CrossRef]

38. Edmunds, K.; Gíslason, M.; Sigurðsson, S.; Guðnason, V.; Harris, T.; Carraro, U.; Gargiulo, P. Advanced quantitative methods in correlating sarcopenic muscle degeneration with lower extremity function biometrics and comorbidities. PLoS ONE 2018, 13, e0193241. [CrossRef]

39. Steib, S.; Hentschke, C.; Welsch, G.H.; Pfeifer, K.; Zech, A. Effects of fatiguing treadmill running on sensorimotor control in athletes with and without functional ankle instability. Clin. Biomech. 2013, 28, 790-795. [CrossRef]

40. Wright, K.E.; Lyons, S.; Navalta, J.W. Effects of exercise-induced fatigue on postural balance: A comparison of treadmill versus cycle fatiguing protocols. Graefes Arch. Clin. Exp. Ophthalmol. 2012, 113, 1303-1309. [CrossRef]

41. Pau, M.; Mereu, F.; Melis, M.; Leban, B.; Corona, F.; Ibba, G. Dynamic balance is impaired after a match in young elite soccer players. Phys. Ther. Sport 2016, 22, 11-15. [CrossRef] [PubMed]

42. Lacey, M.; Donne, B. Does fatigue impact static and dynamic balance variables in athletes with a previous ankle injury? Int. J. Exerc. Sci. 2019, 12, 1121-1137. [PubMed] 
43. Paillard, T. Effects of general and local fatigue on postural control: A review. Neurosci. Biobehav. Rev. 2012, 36, 162-176. [CrossRef] [PubMed]

44. Šarabon, N.; Löfler, S.; Hosszu, G.; Hofer, C. Mobility test protocols for the elderly: A methodological note. Eur. J. Transl. Myol. 2015, 25, 253-256. [CrossRef]

45. De La Motte, S.J.; Lisman, P.; Gribbin, T.C.; Murphy, K.; Deuster, P.A. Systematic review of the association between physical fitness and musculoskeletal injury risk. J. Strength Cond. Res. 2019, 33, 1723-1735. [CrossRef]

46. Šarabon, N.; Smajla, D.; Kozinc, Ž.; Kern, H. Speed-power based training in the elderly and its potential for daily movement function enhancement. Eur. J. Transl. Myol. 2020, 30, 8898. [CrossRef]

47. Ponce-Bravo, H.; Ponce, C.; Feriche, B.; Padial, P. Influence of two different exercise programs on physical fitness and cognitive performance in active older adults: Functional resistance-band exercises vs. recreational oriented exercises. J. Sports Sci. Med. 2015, 14, 716-722.

48. Nejc, S.; Loefler, S.; Cvecka, J.; Sedliak, M.; Kern, H. Strength training in elderly people improves static balance: A randomized controlled trial. Eur. J. Transl. Myol. 2013, 23, 85-89. [CrossRef]

49. De Venuto, D.; Mezzina, G. High-specificity digital architecture for real-time recognition of loss of balance inducing fall. Sensors 2020, 20, 769. [CrossRef]

50. McGuine, T.A.; Greene, J.J.; Best, T.; Leverson, G. Balance as a predictor of ankle injuries in high school basketball players. Clin. J. Sport Med. 2000, 10, 239-244. [CrossRef]

51. Wang, H.K.; Chen, C.H.; Shiang, T.Y.; Jan, M.H.; Lin, K.H. Risk-factor analysis of high school basketball-player ankle injuries: A prospective controlled cohort study evaluating postural sway, ankle strength, and flexibility. Arch. Phys. Med. Rehabilit. 2006, 87, 821-825. [CrossRef] [PubMed]

52. Riemann, B.L.; Davies, G.J. Limb, sex, and anthropometric factors influencing normative data for the biodex balance system SD athlete single leg stability test. Athl. Train. Sports Health Care 2013, 5, 224-232. [CrossRef]

53. Hamlin, M.J.; Draper, N.; Blackwell, G.; Shearman, J.P.; Kimber, N.E. Determination of maximal oxygen uptake using the bruce or a novel athlete-led protocol in a mixed population. J. Hum. Kinet. 2012, 31, 97-104. [CrossRef] [PubMed]

54. Borg, G.A. Psychophysical bases of perceived exertion. Med. Sci. Sports Exerc. 1982, 14, 377-381. [CrossRef]

55. Cunha, F.; Midgley, A.; Monteiro, W.D.; Farinatti, P. Influence of cardiopulmonary exercise testing protocol and resting VO2 assessment on \%HRmax, \%HRR, \%VO2 max and \%VO2R relationships. Int. J. Sports Med. 2010, 31, 319-326. [CrossRef]

56. Susco, T.M.; McLeod, T.C.V.; Gansneder, B.M.; Shultz, S.J. Balance recovers within 20 min after exertion as measured by the balance error scoring system. J. Athl. Train. 2004, 39, 241-246.

57. Cetin, N.; Bayramoglu, M.; Aytar, A.; Sürenkök, Ö.; Yemisci, O.U. Effects of lower-extremity and trunk muscle fatigue on balance. Open Sports Med. J. 2008, 2, 16-22. [CrossRef]

58. Fox, Z.G.; Mihalik, J.P.; Blackburn, J.T.; Battaglini, C.L.; Guskiewicz, K.M. Return of postural control to baseline after anaerobic and aerobic exercise protocols. J. Athl. Train. 2008, 43, 456-463. [CrossRef]

59. Ishizuka, T.; Hess, R.A.; Reuter, B.; Federico, M.S.; Yamada, Y. Recovery of time on limits of stability from functional fatigue in division ii collegiate athletes. J. Strength Cond. Res. 2011, 25, 1905-1910. [CrossRef]

60. Pau, M.; Laconi, I.; Leban, B. Effect of fatigue on postural sway in sport-specific positions of young rhythmic gymnasts. Sport Sci. Health 2020, 17, 1-8. [CrossRef]

61. Farzami, A.; Anbarian, M. The effects of fatigue on plantar pressure and balance in adolescent volleyball players with and without history of unilateral ankle injury. Sci. Sports 2020, 35, 29-36. [CrossRef]

62. Steinberg, N.; Eliakim, A.; Zaav, A.; Pantanowitz, M.; Halumi, M.; Eisenstein, T.; Meckel, Y.; Nemet, D. Postural balance following aerobic fatigue tests: A longitudinal study among young athletes. J. Mot. Behav. 2016, 48, 332-340. [CrossRef] [PubMed]

63. Yaggie, J.; Armstrong, W.J. Effects of lower extremity fatigue on indices of balance. J. Sport Rehabilit. 2004, 13, 312-322. [CrossRef]

64. Matsuda, S.; Demura, S.; Uchiyama, M. Centre of pressure sway characteristics during static one-legged stance of athletes from different sports. J. Sports Sci. 2008, 26, 775-779. [CrossRef]

65. Nardone, A.; Tarantola, J.; Giordano, A.; Schieppati, M. Fatigue effects on body balance. Electroencephalogr. Clin. Neurophysiol. Mot. Control. 1997, 105, 309-320. [CrossRef] 
66. Yamada, R.K.F.; Arliani, G.G.; Almeida, G.P.L.; Venturine, A.M.; Dos Santos, C.V.; Astur, D.C.; Cohen, M. The effects of one-half of a soccer match on the postural stability and functional capacity of the lower limbs in young soccer players. Clinics 2012, 67, 1361-1364. [CrossRef]

67. Greig, M.; Walker-Johnson, C. The influence of soccer-specific fatigue on functional stability. Phys. Ther. Sport 2007, 8, 185-190. [CrossRef]

68. Gioftsidou, A.F.; Malliou, P.; Pafis, G.; Beneka, A.; Godolias, G. Effects of a soccer training session fatigue on balance ability. J. Hum. Sport Exerc. 2011, 6, 521-527. [CrossRef]

69. Frisch, A.; Urhausen, A.; Seil, R.; Croisier, J.L.; Windal, T.; Theisen, D. Association between preseason functional tests and injuries in youth football: A prospective follow-up. Scand. J. Med. Sci. Sports 2011, 21, e468-e476. [CrossRef]

70. Willems, T.M.; Witvrouw, E.; Delbaere, K.; Mahieu, N.; De Bourdeaudhuij, L.; De Clercq, D. Intrinsic risk factors for inversion ankle sprains in male subjects: A prospective study. Am. J. Sports Med. 2005, 33, 415-423. [CrossRef] [PubMed]

71. Kraemer, R.; Knobloch, K. A soccer-specific balance training program for hamstring muscle and patellar and achilles tendon injuries. Am. J. Sports Med. 2009, 37, 1384-1393. [CrossRef] [PubMed]

72. Hübscher, M.; Zech, A.; Pfeifer, K.; Hänsel, F.; Vogt, L.; Banzer, W. Neuromuscular training for sports injury prevention. Med. Sci. Sports Exerc. 2010, 42, 413-421. [CrossRef] [PubMed]

(C) 2020 by the authors. Licensee MDPI, Basel, Switzerland. This article is an open access article distributed under the terms and conditions of the Creative Commons Attribution (CC BY) license (http://creativecommons.org/licenses/by/4.0/). 